\title{
¿PROGRESA MORALMENTE EL GÉNERO HUMANO?
}

\section{DOES MANKIND MORALLY PROGRESS?}

\author{
Fernando GARCÍA MARTíN* \\ UNED
}

Resumen: Tomando como marco de referencia la filosofía crítica kantiana, el artículo se plantea la cuestión del progreso moral de la humanidad. En primer lugar, examina las dificultades que en el contexto de tal filosofía presenta la pretensión de avanzar algo en lo moral. A continuación, aborda la posible contradicción existente entre la idea de progreso y la adscripción kantiana de lo moral al ámbito nouménico. Considera las diferentes alusiones que en la obra kantiana se encuentran en defensa de la tesis que sostiene el progreso moral del género humano, examinando los argumentos a favor y en contra de ellas. Finalmente, establece el estatus que debe tener en el contexto kantiano de reflexión la anticipación del posible progreso moral de la humanidad y la manera como éste habría de producirse.

Palabras Clave: Kant, moralidad, progreso, legalidad, entusiasmo, Iglesia invisible.

AвSTRACT: This paper raises the question of moral progress of humanity taking the Kantian critical philosophy as framework. Firstly, it examines the difficulties the claim presents, in the context of such philosophy, to somewhat progress in morality. Then it discusses the possible contradiction between the idea of progress and the Kantian ascription of moral to the noumenic sphere. It takes into account the different references in Kant's works where the thesis that defends moral progress of mankind is uphold, examining the arguments for and against. Finally, it sets the status the anticipation of the possible moral progress of humanity should have in the Kantian context of reflexion and the way it should take place.

KEYwORDs: Kant, progress, morality, legality, enthusiasm, invisible Church.

\footnotetext{
* Alumno de doctorado, C/Constancia 30 1 Izq. 28002 Madrid, fgarcia1019@alumno.uned.es.
} 


\section{Introducción}

La problemática en torno al progreso o no del género humano es uno de los temas que ha sido frecuente objeto de reflexión por parte del pensamiento filosófico. Ahora bien, la multiplicidad de ámbitos sobre los que se despliega la acción humana hace que el término "progreso" admita varias adjetivaciones. Así, por ejemplo, se puede hablar del progreso científico, del tecnológico y técnico, del histórico, del legal, etc. En el presente artículo el foco de atención lo constituirá exclusivamente el progreso humano en el orden de la moralidad.

Pero aun centrándonos en el progreso moral del género humano, la variedad de enfoques desde los que se ha abordado filosóficamente la moralidad hace que en lo que atañe a la cuestión del progreso moral de la humanidad también se cuente con una gran diversidad de posicionamientos, una buena muestra de las cuales puede encontrarse en el artículo: «Is there progress in Morality?» de Dale Jamieson, planteando como ineludible una segunda restricción a la hora de perfilar el objeto de consideración.

A lo largo de las páginas que siguen, la filosofía crítica kantiana se constituye como la perspectiva desde la que se abordará la problemática en torno al progreso moral del género humano. Lo que se tratará de investigar será por tanto si, contemplada la marcha histórica de la humanidad desde el punto de vista que la moralidad introduce en el discurso filosófico, puede hablarse o no con suficiente fundamento de que en este discurrir temporal se asiste a un progreso en el orden de los logros morales del género humano, o, por el contrario, tal progreso no puede ser sostenido, bien porque se constata que no se da, bien porque se estima que no se dispone de elementos suficientes que legitimen la defensa de su efectividad.

\section{La dificultad de la temática del progreso moral}

El tratamiento de la problemática en torno al progreso moral del género humano en la filosofía crítica presenta una primera dificultad, consistente en la falta de planteamiento temático por parte de Kant de esta cuestión en sus Críticas. Por otra parte, si se atiende exclusivamente a los títulos de sus obras, esta temática tan solo es mencionada en el opúsculo «Si el género humano se encuentra en progreso constante hacia mejor» (1798), e incluso, si se repara en 
lo tardío de la publicación del mismo, una vez que las Críticas ya habían hecho su aparición, parecería no haber sido objeto de consideración prioritaria por parte de Kant. Pero, si se tienen en cuenta las frecuentes alusiones al progreso que dentro de su producción filosófica se hacen ${ }^{1}$, la cuestión del progreso del género humano se configura indudablemente como un objeto digno de su consideración.

Una buena muestra del interés kantiano en esta temática se encuentra en las primeras líneas del tercer apartado del ensayo «En torno al tópico: “Tal vez eso sea correcto en teoría, pero no sirve para la práctica” (1793):

¿Hay que amar al género humano en su totalidad o es éste un objeto que se ha de contemplar con enojo, un objeto al que ciertamente se desea todo bien (para no convertirse en misántropo) pero sin esperarlo jamás de él, por lo cual será mejor apartar de él la vista? La respuesta a esta pregunta depende de la que se dé a esta otra: ¿Hay en la naturaleza humana disposiciones de las cuales se pueda desprender que la especie progresa siempre a mejor, y que el mal del presente y del pasado desaparecerá en el bien del futuro? Porque entonces podemos amar a la especie, aunque sea siquiera en su constante acercamiento al bien; de lo contrario, tendríamos que odiarla o despreciarla, diga lo que diga en contra de esto la afectación de una filantropía universal (que sería entonces, a lo sumo, un amor de benevolencia, no de complacencia). Pues, aunque se haga el mayor de los esfuerzos para que el amor surja dentro de uno mismo, no se puede evitar el odio hacia lo que es y sigue siendo malo (sobre todo hacia esa maldad que consiste en una premeditada violación recíproca de los más sacrosantos derechos del hombre). Y no precisamente para hacer mal a los hombres, pero sí para tener con ellos el menor trato posible (Kant, 1993: 51-52).

Sin embargo, la principal dificultad a la hora de abordar esta problemática radica en que la moralidad humana en el planteamiento kantiano se mantiene al margen de las consideraciones en términos empíricos, por lo que la dilucidación

1 La búsqueda del término "Fortschritt» en la edición digital de sus obras devuelve 66 hallazgos en 55 capítulos de las mismas. 
de si el progreso en este ámbito realmente se da o no únicamente podrá ser llevada a cabo de manera indirecta, y no del modo directo en términos de conocimiento objetivo como, al menos en primera instancia, podría parecer preferible hacerlo. Al respecto, nuestro autor llega incluso a apuntar que «la verdadera moralidad de nuestros actos (mérito y culpa), incluso la de nuestra propia conducta, permanece, pues, oculta para nosotros» (Kant, 1989: 474-475; también en Kant, 1986: 68-69; Kant, 2002b: 246).

Así pues, si no resulta posible que el agente mismo efectúe una evaluación moral de su acción que suponga un conocimiento objetivo en este ámbito, más difícil si cabe resultará hacerlo en lo que se refiere al resto de la humanidad, y mucho más incluso en relación con la marcha histórica de ésta en su conjunto, al menos cuando ella se encuentre sometida exclusivamente a la "fría» observación empírica que debe caracterizar al investigador científico, ya que «no disponemos más que de datos empíricos (experiencias) donde basar esta predicción [la de si se producirá un progreso hacia mejor en el género humano]; a saber, sobre la causa física de nuestras acciones, en la medida que ocurren y son, por lo mismo, también fenómenos, no sobre la causa moral, que contiene el concepto moral de lo que debiera ocurrir, único que puede ser trazado puro, a priori» (Kant, 1992b: 114).

\section{Distinción entre el progreso moral del individuo y el del género humano}

La cuestión del progreso moral en términos de una posible anticipación de si éste se producirá o no de manera necesaria en cada uno de los individuos no es abordada por Kant. El motivo de esta ausencia de planteamiento tal vez se encuentre en la radical condición libre del ser humano defendida, entre otros lugares, en La Religión dentro de los límites de la mera razón (1793), que lo capacita para obrar tanto en el sentido del bien como en el del mal moral, por lo que carecería de fundamento la pretensión de decir algo a priori acerca de si los seres humanos, considerados como individualidades, progresarán o no moralmente de manera necesaria.

En todo caso, nuestro autor concibe que la conversión moral «no puede hacerse mediante reforma paulatina, en tanto la base de las máximas permanece impura, sino que tiene que producirse mediante una revolución en la intención 
del hombre (un paso a la máxima de la santidad de ella); y sólo mediante una especie de renacimiento, como por una nueva creación (Juan, III, 5; cf. I Moisés, I, 2) y un cambio del corazón, puede el hombre hacerse un hombre nuevo» (Kant, 1986: 56), lo que supone que la entrada de cada uno de los hombres en la senda del progreso moral solamente pueda llevarse a efecto mediante un salto cualitativo hacia una nueva disposición del ánimo (Gemüt) y no mediante un mero aumento cuantitativo en una cierta disposición con la que ya se contase de antemano, quedando dificultada aún más de esta manera la pretendida anticipación que se pudiera hacer en relación con el progreso moral del género humano.

No obstante, al modo como Kant se atrevió a «concebir la esperanza, a pesar de que las causas de los mismos pueden yacer profundamente ocultas, de que, si ella [la historia] contempla el juego de la libertad humana en grande, podrá descubrir en él un curso regular, a la manera como eso que, en los sujetos singulares, se presenta confuso e irregular a nuestra mirada, considerado en el conjunto de la especie puede ser conocido como un desarrollo continuo, aunque lento, de sus disposiciones originales» (Kant, 1992a: 39-40), sea posible tal vez anticipar respecto del género humano en su totalidad, en relación con la cuestión de su progreso moral, lo que no pudo ser adelantado cuando el objeto de consideración fueron los seres humanos tomados en su individualidad.

\section{Las hipótesis en torno al progreso del género humano}

$\mathrm{Al}$ comienzo del ensayo «Si el género humano...» Kant presenta tres hipótesis posibles respecto del "progreso» humano: el terrorismo moral, el eudemonismo y el abderitismo (Kant, 1992b: 98). Del análisis inicial de ellas cabe destacar que cada una posee elementos propios que permiten hablar tanto a su favor como en su contra, por lo que la determinación final definitiva por una concreta queda en el aire, pero ya decantada hacia aquélla que al menos posibilite el progreso moral del género humano, o al menos no lo impida, por cuanto lo que la razón práctica le exige a cada individuo moral concreto es que debe (soll) progresar moralmente. Por este motivo, puede afirmarse que las iniciales «hipótesis» respecto del progreso moral se transforman en "posturas» ante la posibilidad de éste, pues el individuo moral no puede permanecer indiferente ante ellas, sino que al inclinarse cognoscitivamente a favor de alguna deberá también comprometerse activamente en su realización. 
La primera hipótesis planteada es la del «terrorismo moral». Según ella, el género humano se encontraría "en un continuo retroceso hacia peor» (Kant, 1992b: 98). La objeción que nuestro autor plantea a esta hipótesis es que «la caída a peor no puede continuar sin cesar en la historia humana, porque al llegar a cierto punto acabaría destruyéndose a sí misma» (Kant, 1992b: 99).

La segunda hipótesis es la del «eudemonismo», que defiende que habrá un «progreso continuo hacia mejor en lo que se refiere a su destino moral [el del género humano]» (Kant, 1992b: 98). El reparo que Kant presenta a esta hipótesis, que puede entenderse que mantiene una relación de contradicción lógica con la anterior (la del terrorismo moral), hace hincapié en que «la masa de bien y de mal atribuida a nuestra naturaleza permanece en la índole siempre la misma, y no puede aumentar o disminuir en un mismo individuo", por lo que, puesto que «los efectos no pueden exceder la potencia de la causa actuante; y, así, tampoco el cuánto de bien mezclado en el hombre con el mal puede exceder cierta medida por encima de la cual se elevara el hombre y progresara constantemente hacia mejor», resulta que, «el eudemonismo, con sus vigorosas esperanzas, parece, pues, insostenible, y prometernos muy poco a favor de una historia humana previsora con respecto a un progreso indefinido" (Kant, 1992b: 99-100). Por ello, para que se pudiese hablar de un progreso indefinido en el orden de la moralidad se requeriría esa especie de "nueva creación» a la que nuestro autor alude en este mismo ensayo (Kant, 1992b: 114-115).

Parece entonces que todo debiera apuntar hacia el "abderitismo», consistente en «un eterno estancamiento de su actual valor moral [el del hombre]» (Kant, 1992b: 98), como la hipótesis más plausible, pues, «el carácter de nuestra especie es agitada locura. Entra rápidamente en los carriles del bien, pero no perdura, sino que, para no hallarse vinculada a un único fin, por mero amor al cambio, invierte el plan del progreso, edifica para derribar, y se da a la tarea más desesperada, a cargar la piedra de Sísifo montaña arriba para dejarla rodar en un momento» (Kant, 1992b: 100-101).

El «abderitismo moral» se plantea de esta forma como la hipótesis más plausible ("Acaso esta opinión disponga de la mayoría de los votos a su favor» (Kant, 1992b: 100-101)), tanto en lo relativo al nivel individual de consideración como por lo que atañe al tratamiento de la humanidad en su conjunto. El motivo de su plausibilidad se encuentra en la condición mixta del hombre como ser perteneciente a la vez a dos mundos (el nouménico y el fenoménico), motivo por el cual podría pensarse que, aunque algunos seres humanos puedan llevar a cabo 
progresos en el orden moral, su efecto sobre el conjunto de la especie quedase neutralizado por el efecto sobre esta misma moralidad global de aquéllos que no se hayan separado del primado de la aspiración a la felicidad como eje director de su comportamiento, bien por propia iniciativa o por incapacidad para hacerlo. $\mathrm{El}$ «abderitismo» vendría a ser así la conclusión «estadística» a la que se llegaría tras una consideración "ponderada» de la naturaleza humana, poseyendo además la virtud de ser capaz de resolver las contradicciones internas y entre sí que acarreaban las otras dos hipótesis anteriormente esbozadas (el «terrorismo moral» y el «eudemonismo»), por lo que parece que habría de ser la postura por la que finalmente hubiese de inclinarse la razón.

No obstante, aunque el «abderitismo moral» se presente como la hipótesis más plausible desde un punto de vista "estadístico», las consideraciones kantianas de índole práctica presentan dos objeciones al mismo. La primera se hace en el ensayo "Si el género humano...», cuando, de manera un tanto peyorativa, nuestro autor alude a que si esta oscilación entre el bien y el mal se diese se tendría un "perpetuo dar vueltas en círculo alrededor del mismo punto" (Kant, 1992b: 100-101) (lo que suena como una situación carente de sentido, por no encontrase dirigida la actividad hacia fin alguno) y a que ese amalgamiento entre el bien y el mal «traería como consecuencia la inacción (que en este caso llamamos estancamiento) [lo cual contradiría la propia naturaleza humana como la de un ser dirigido a la acción]; agitación vacía en la que el bien y el mal se alternan, de suerte que el espectáculo del afán sobre la tierra de la humanidad consigo misma, a lo que más se pareciera sería a una farsa de locos, lo que no le haría acreedora ante los ojos de la razón de una estimación mayor de la concedida a la actividad de otras especies animales, que tienen en su favor llevar el juego con menos costo y sin derroche de razón» (Kant, 1992b: 100-101). La segunda, que tal vez sea la más decisiva en su contra, se encuentra en el ensayo «En torno al tópico...», por medio de la indicación kantiana de que «si es espectáculo digno de una divinidad el de un hombre virtuoso luchando contra adversidades y tentaciones que inducen al mal, sin arredrase ante ellas a pesar de todo, también es un espectáculo sumamente indigno (no diré ya de una divinidad, sino incluso del más común de los hombres, siempre que sea bienintencionado) el que ofrece periódicamente el género humano ascendiendo unos cuantos pasos hacia la virtud para recaer poco después, y siempre con igual profundidad, en el vicio y la miseria» (Kant, 1993: 53). 


\section{Las contradicciones internas de la idea de progreso en el marco de la filosofía kantiana}

Unidas a las dificultades hasta ahora presentadas en relación con la aspiración de anticipar algo acerca del progreso moral o no del género humano, debe tenerse también en cuenta que, tal como Pauline Kleingeld recoge en su artículo «Kant, History, and the Idea of Moral Development», pudiera ocurrir que la idea misma de un progreso en lo moral resultase contradictoria con el planteamiento mismo de la moralidad que nuestro autor lleva a efecto en su filosofía crítica. La causa de tal contradicción, que se diversifica según esta autora dando lugar a los problemas de la validez universal (the universal validity problem), de la atemporalidad (the atemporality problem) y de la igualdad moral (the moral equality problem) (Kleingeld, 1999: 59), se encontraría en que el ámbito nouménico en el que se desarrolla la moralidad no tiene a la temporalidad como una de sus dimensiones, pero el término "progreso» se encuentra asociado ineludiblemente con el tiempo mismo como referente imprescindible de su significado y posibilidad.

Ahora bien, esta problemática creo que queda resuelta de manera convincente si, como sostiene Kleingeld en defensa de la presencia de la idea del progreso moral en la filosofía kantiana, se sostiene que todos los hombres comparten una idéntica constitución como seres libres, consistente en la posesión de una predisposición para la moralidad, y que por tanto la moralidad de la especie permanece inalterada a través del tiempo, siendo sin embargo el uso que se hace en cada uno de los tiempos históricos de esta predisposición originaria común por parte de cada uno de los individuos concretos y de su conjunto lo que deviene temporalmente (Kleingeld, 1999: 70-71).

\section{Los ámbitos desde los que se plantea la cuestión del progreso del género humano}

La cuestión de si el género humano progresa o no moralmente no puede ser abordada teóricamente, pues en el planteamiento kantiano el modo de ser de la moralidad no participa de las condiciones espaciotemporales y categoriales que hacen posible el conocimiento objetivo. Pero, además, ocurre que, incluso si la experiencia pudiese decir algo al respecto, no podría ser lo anticipado establecido de manera concluyente, pues «nadie podría asegurar que no sea ahora, precisamente, el momento en que, gracias a las disposiciones físicas de nuestra 
especie, los tiempos comiencen a retroceder; y, por el contrario, tampoco en el caso de que fuera retrocediendo y acelerando su marcha a peor, podríamos asegurar que no se presentara un recodo en el camino (punctum flexus contrarii) en el cual, gracias a las disposiciones morales de nuestra especie, se enderezara su marcha hacia mejor" (Kant, 1992b: 101). Por este motivo, Kant concluye de manera tajante que «no es posible resolver directamente la cuestión del progreso por la experiencia» (Kant, 1992b: 101). Sin embargo, puesto que nuestro autor plantea como objetivos de su filosofía dar respuesta no solamente a la pregunta acerca de qué se puede saber (was kann ich wissen?), sino también a las cuestiones relativas a qué se debe hacer (was soll ich tun?) y qué cabe esperar (was darf ich hoffen?) (Kant, 1989: 629-630; Kant, 2000: 92), será preciso abordar la temática del progreso moral o no de la humanidad también desde los ámbitos de discurso abiertos por estas dos últimas preguntas.

En primer lugar se encuentra la cuestión ya apuntada acerca de qué se debe hacer (was soll ich tun?) en relación con el progreso moral del género humano, que remite directamente al ámbito práctico de la filosofía kantiana.

En la Doctrina de la virtud de la Metafísica de las Costumbres (1797) Kant establece como un deber hacia sí mismo el de «elevar la propia perfección moral (eigene Vollkommenheit)» (Kant, 2002b: 314-315), lo que puede interpretarse como indicando que cada hombre en particular debe comprometerse en el sentido de favorecer que el género humano progrese moralmente. Pero en esta misma obra no se dice (como cabría esperar según lo anteriormente expuesto) que el fin que hacia los demás debamos tener sea el de su perfección moral, sino que establece que ese fin sólo puede ser el de su felicidad (fremde Glückseligkeit) (Kant, 2002b: 237-240, 244-248).

Sin embargo, en sus Lecciones de Etica (1784-1785), nuestro autor apunta que «el destino final del género humano es la perfección moral en tanto que ésta sea realizada mediante la libertad humana» (Kant, 2002a: 301). En este caso, puesto que el término "destino" (Bestimmung) hace referencia a una posible situación o estado futuro a cuya realización sea preciso contribuir con el esfuerzo que se haga en el presente, podría suponerse que la actitud del hombre respecto del progreso del género humano no podrá ser la actitud parcialmente pasiva de únicamente procurar su propio progreso moral, sino que además deberá participar activamente en la tarea de que sea la humanidad la que como un todo progrese en este sentido. 
La solución a esta aparente contradicción pienso que debe buscarse en el añadido kantiano de que la perfección moral del género humano ha de ser realizada «mediante la libertad humana». Hacer de la perfección moral de los demás un fin que cada uno hubiese de perseguir de manera individual supondría dar entrada al «moralismo» en la ética, pues permitiría que cada uno se relacionase con los demás tratando de que éstos hiciesen propia la «materialidad» de su código moral particular. Si así se procediese, no se estaría teniendo en cuenta la autonomía moral que cada ser humano puede ejercer como consecuencia de su libertad originaria, sino que se estaría propiciando un comportamiento heterónomo de los otros en las cuestiones morales. Así pues, exclusivamente respetando la autonomía legisladora de cada ser humano es como la perfección moral podrá alcanzar a constituirse en el «destino final» de la humanidad.

\section{El necesario progreso del género humano en el orden de la legalidad}

En el planteamiento kantiano, la manera como el género humano podrá contribuir a su progreso moral no supone un modo directo de hacerlo sino uno indirecto. Éste consiste fundamentalmente en el establecimiento de un sistema legal justo que regule las relaciones que entre sí mantengan los hombres, tanto individualmente considerados, en cuanto son miembros de sus respectivos Estados, como en lo que atañe a las relaciones que estos Estados de los que forman parte establezcan mutuamente. Si este sistema legal justo consiguiese implementarse, tanto a nivel estatal como al internacional, habrían quedado sentadas las bases para el progreso moral del género humano, aunque en principio ello no tenga por qué implicar que tal progreso moral haya de producirse de manera necesaria e ineludible.

Así como Kant no se compromete explícitamente en lo relativo a la anticipación del progreso moral del género humano en términos positivos, cuando se refiere a su progreso legal sí que lo hace, anticipando que los agrupamientos que los seres humanos establezcan se producirán dando lugar a sistemas legales en los que las libertades originarias de los individuos queden armonizadas en el interior de la sociedad mediante mecanismos de limitación recíproca de las mismas. En la base de la legitimación de tal anticipación se encuentra la existencia de un mecanismo, el del «antagonismo» (Antagonism) (Kant, 1992a: 46), que por medio de la «insociable sociabilidad» (ungesellige Geselligkeit) humana y de la guerra actúa como motor de la historia, haciendo que, aunque los hombres puedan preferir 
encontrarse en un estado de libertad salvaje (estado de naturaleza), sea la propia Naturaleza (die große Künstlerin Natur: natura daedala reum) o Providencia (Vorsehung) quien les haga unirse (Kant, 1985: 31; Kant, 1993: 58), dando fin a esa situación de amenaza mutua en la que se encontraban anteriormente, por medio de un proceso de orden legal que suponga el reconocimiento recíproco que hagan de sus libertades externas (Kant, 1991: 420).

Pero, puesto que el mecanismo del antagonismo actúa de manera ciega, no necesariamente se podrá concluir también que todo progreso en el orden de la legalidad lleve aparejado un progreso proporcional en el de la moralidad, recordando nuestro autor al respecto que «el problema del establecimiento del Estado tiene solución, incluso para un pueblo de demonios, por muy fuerte que suene (siempre que tengan entendimiento)» (Kant, 1985: 38).

En su artículo antes referido, Pauline Kleingeld indica que Höffe y Yovel sostienen que este aumento de la legalidad de las acciones no tiene por qué encontrase unido a un aumento proporcional de su moralidad, siendo la autora de este artículo de la opinión de que tal aseveración sólo puede defenderse a partir de un texto perteneciente a El conflicto de las Facultades VII, 92, por lo que carecería de suficiente fundamento dentro de la filosofía kantiana (Kleingeld, 1999: 77). Esta carencia es la que da pie a Kleingeld a proceder a la defensa de que unido a este progreso en el orden legal se encontrará también uno equivalente en el moral.

\section{Los indicios a favor del progreso moral del género humano}

Aunque no de manera concluyente, considero no obstante que sí hay indicios de que Kant pensó que este aumento en la legalidad en el mundo dará lugar a uno equivalente en la moralidad y que ellos contribuyen a la justificación de la posición que defiende que sí habrá un progreso moral del género humano a lo largo de la historia. Estos indicios no poseen validez desde un punto de vista teórico (was kann ich wissen?), ya que, como se ha repetido en varias ocasiones en el presente artículo, no es posible anticipar teóricamente lo que ocurrirá en el ámbito moral. Sin embargo, poseen un indudable valor práctico, consistente en la apelación que hacen a cada uno de los hombres para que se comporten moralmente (was soll ich tun?), uniendo además a esta compulsión la fundamentada confianza de que sus esfuerzos se verán recompensados con el éxito (was darf ich hoffen?). 


\subsection{El optimismo kantiano en torno al triunfo final del bien}

En primer lugar se encuentra un cierto optimismo kantiano de corte ilustrado que le lleva a afirmar que «el mal moral posee la característica, inseparable de su naturaleza, de contradecirse y destruir sus propios propósitos (sobre todo en relación con otros malvados) y así deja paso, aunque lentamente, al principio (moral) del bien» (Kant, 1985: 58), de donde podría resultar plausible que cabría inferir que los hombres tanto individualmente como colectivamente, es decir, como género humano, progresarán moralmente.

Este optimismo kantiano tiene una consecuente manifestación en el establecimiento como una de sus premisas básicas a la hora de afrontar las cuestiones de índole teleológico la de que "todas las disposiciones naturales de una criatura están destinadas a desarrollarse alguna vez de manera completa y adecuada» (Kant, 1992a: 42; también en Kant, 1990: 55). Esta confianza en el poder de la razón es la que permitiría concluir que, si toda disposición racional está llamada a realizarse, siendo además que, puesto que la razón no resulta suficientemente eficaz a la hora de proveer al hombre para la felicidad, mostrándose incluso para tal tarea el instinto como más adecuado (Kant, 1990: 55-56), su finalidad haya de encontrarse en su uso práctico. Ahora bien, el problema con el que se encuentra este razonamiento es que el uso práctico de la razón no siempre tiene al bien moral como su resultado, sino que a veces la consecuencia de tal uso es el mal, pues en el fondo la libertad humana puede actuar tanto en un sentido como en el otro, como nuestro autor expone en la primera parte de la Religión.

Deben buscarse por tanto elementos complementarios que fundamenten esta confianza kantiana en la autodestrucción del mal en el mundo.

Uno de ellos puede partir de la indicación según la cual para el seguimiento de la ley moral no se precisan ni especiales conocimientos ni especial agudeza (Kant, 1990: 67-68). Esta simplicidad en la dirección de la razón hacia el bien moral contrastaría con las complicaciones inherentes al uso de la razón cuando el principio rector que la anima es el de la felicidad, debidas a que el concepto de felicidad que cada uno pueda hacerse para sí mismo no resulte del todo claro y distinto, sino que se presente indefinido (Kant, 1991: 416-417). Por este motivo, podría ocurrir que en la búsqueda de la felicidad se constatase la existencia de contradicciones en el concepto que nos hagamos de ella (Kant, 1990: 61-62). Estas contradicciones serían las que finalmente terminarían por autodestruir la 
voluntad del que ponga en su obtención el objetivo final de su existencia, que es a lo que podría aludir la indicación kantiana de que el mal termina por destruirse a sí mismo.

En relación con esta anotación, puede plantearse de qué manera este proceso «traumático» de aprendizaje al que se ven sometidas las voluntades de cada uno de los individuos concretos puede dar lugar a un progreso moral del género humano. Pienso que el modo como lo puede hacer es uno indirecto, consistente en que estas experiencias autodestructivas facilitan que cada uno de los individuos reflexione acerca de la posición que en el orden jerárquico debe asignar a cada una de las motivaciones posibles a la hora de obrar, pasando a atender en menor grado las consideraciones pragmáticas, o incluso llegando a conceder una preeminencia valorativa a las específicamente morales, lo que vendría a suponer el progreso moral de ese individuo concreto. Puesto que esto último es susceptible de acontecer en cada uno de los componentes del género humano, ya que la experiencia que lo motiva posee carácter general, se tendría como consecuencia suya un incremento global de la moralidad en el mundo resultante de la adición de cada uno de los previsibles progresos morales de las individualidades.

\subsection{La atribución de la carga de la prueba al adversario}

En segundo lugar se dispone de la observación kantiana de que «es el adversario de ella [la tesis de que el género humano progresa a mejor en lo concerniente al fin moral de su existencia] quien ha de proporcionar la prueba» (Kant, 1993: 53-54). El modo de proceder de nuestro autor en la justificación de este requerimiento constituye una síntesis clara de su planteamiento completo en esta temática. Por un lado, se encuentra que el progreso moral quede constituido como un deber moral, siendo ésta una apelación que la razón práctica le hace al hombre de manera incondicionada. Por otro, que baste con que no se encuentren impedimentos objetivos para este progreso, los cuales habrían de venir dados por la razón teórica, para que se sostenga que el cumplimiento de tal tarea es además posible, lo que puede actuar a su vez reforzando la motivación de índole moral e impeliendo al hombre a que no ceje en el empeño de mejorarse moralmente (Kant, 1993: 53-54, 55; también en Kant, 1985: 41; Kant, 2002b: 194-196). Es por ello que Kant concluye diciendo que «los argumentos empíricos contra el éxito de estas resoluciones tomadas por esperanza son aquí del todo inoperantes; la suposición de que, cuanto hasta ahora aún no se ha logrado, sólo por eso 
tampoco se va a lograr jamás, no autoriza en modo alguno a desistir de propósitos pragmáticos o técnicos (como, por ejemplo, el de viajar por el aire con globos aerostáticos), y menos todavía de un propósito moral, pues respecto de este último basta con que no se haya demostrado la imposibilidad de su realización para que constituya un deber» (Kant, 1993: 55).

\subsection{La mayor «sensibilidad» moral del presente}

En tercer lugar, el que la crítica creciente a la que la razón somete la época presente sea un indicio para Kant de que los hombres del momento presente son más estrictos que los del pasado en la valoración de su propia época histórica (Kant, 1993: 55-56), lo que podría constituir un indicio suficiente de que han progresado moralmente. Sería posible objetar tal vez que la constatación de que la razón en el presente se «escandaliza» más de lo que lo hizo en el pasado se deba a que el presente es más inmoral que el pasado, pero debe tenerse en cuenta que, como se ha apuntado anteriormente, nuestro autor descarta la posibilidad del «terrorismo moral», según el cual habría una cantidad creciente de mal moral en el mundo.

\subsection{El homenaje rendido al "concepto de derecho» por parte de los Estados}

En cuarto lugar, resulta para Kant un hecho que el «homenaje que todos los Estados tributan al concepto de derecho (al menos de palabra) demuestra que se puede encontrar en el hombre una disposición moral más profunda, latente por el momento, a dominar el principio malo que mora en él (que no pude negar) y a esperar esto mismo de los otros» (Kant, 1985: 23). A partir de esta observación podría deducirse que, una vez que nuestro autor ha constatado que en el mundo habrá un aumento de la legalidad, quedase igualmente justificado que se producirá un aumento proporcional de la moralidad en el género humano.

Una objeción posible a este razonamiento encontraría su punto de partida en el supuesto carácter necesario de la conexión que permitiese inferir la moralidad de una acción a partir de su legalidad. De esta manera, nuevamente sería plausible aducir que, puesto que Kant mismo ha dicho que hasta «un pueblo de demonios» se vería forzado, «siempre que tengan entendimiento», a entrar en 
una ordenación legal de sus voluntades (Kant, 1985: 38), no parece que la mera constatación de la creciente legalidad de las acciones humanas pueda traer como consecuencia necesaria también el incremento de su moralidad.

Esta situación de incertidumbre se supera cuando se tiene en cuenta que el ámbito en el que se está produciendo la reflexión kantiana no es el del conocimiento teórico objetivo de lo que «es», sino el de la esperanza que cabría suponer con fundamento una vez que se cumpliesen los preceptos prácticos correspondientes al "deber ser». Por este motivo, aunque nunca pueda alcanzarse un conocimiento teórico acerca de la moralidad de las acciones del género humano en su conjunto y mucho menos uno de este tipo acerca de la evolución de la moralidad en el mundo, esta incapacidad no quita para que se traten de buscar elementos que hagan factible confiar en el triunfo final de aquello que la moral prescribe al ser humano como necesario.

Un elemento que considero que legitima la confianza de que se dará un salto desde la legalidad a la moralidad en el nivel de consideración individual lo constituye la previsible extensión en la sociedad de un modo de pensar legaliforme como consecuencia de la creciente tendencia a la regulación de las relaciones entre sus individuos componentes por medio de códigos legales. Este nuevo modo de pensar haría más probable que los hombres tuviesen en cuenta cada vez más las consideraciones de índole formal a la hora de actuar, lo que finalmente allanaría el camino para que diesen entrada como principio rector de su comportamiento a una ley de carácter formal como es el imperativo categórico. Por este motivo, pese a que Kant no anticipe explícitamente un aumento de la moralidad en el mundo como consecuencia del incremento de la legalidad en el mismo, pienso que no resulta descabellado suponer una extensión de la moralidad en el mundo unida a ese aumento de los «actos buenos de los hombres, que serán más frecuentes y acertados» al que se refiere nuestro autor en «Si el género humano...» concretándolo en que "poco a poco las violencias de los poderosos serán menos frecuentes, la obediencia a las leyes más. Surgirán en la comunidad más acciones benéficas, habrá menos discordia en los procesos, más seguridad en la palabra dada, etc., en parte por motivos de honor, en parte por interés propio bien entendido» (Kant, 1992b: 114). 


\subsection{La "autosuperación» moral del hombre}

En quinto lugar, Kant apunta que «cada uno cree de sí mismo que respetaría el concepto del derecho y lo acataría con fidelidad si pudiera esperar lo mismo de los demás, lo que, en parte, el gobierno le garantiza; con esto se da un gran paso hacia la moralidad (aunque no se dé todavía un paso moral), al adherirse a este concepto del deber por sí mismo sin tomar en cuenta la reciprocidad» (Kant, 1985: 53-54).

No resulta evidente a primera vista determinar en qué consiste según nuestro autor este "gran paso hacia la moralidad». Este avance hacia la moralidad podría estribar, según la interpretación defendida en este artículo, en que cada hombre se emulase y se superase a sí mismo en lo que a su moralidad se refiere. Esta «autosuperación» se presume que sería posible si la ley pública hubiese sido capaz de reprimir las conductas inmorales en un grado tal que impidiese que se manifestasen públicamente, de manera que así cada persona concreta, que de por sí admitiría que se comportaría moralmente con gusto si pudiese suponer que los demás también lo harán, como supone nuestro autor de forma tal vez un tanto bienintencionada, al no encontrar pretexto para no obrar moralmente, pues exteriormente no percibiría la existencia de ejemplos de comportamientos inmorales, terminase por exigirse a sí mismo (interiormente) de manera estricta ser cada vez más «moral» en su modo de obrar.

Tras esta argumentación se encuentra una doble suposición kantiana. En primer lugar, la de que, enfrentándose a todo aquello que se encuentra en una relación de oposición con algo, se favorece el desarrollo positivo de ese algo, al modo como sostiene nuestro autor en la Analítica de la razón pura práctica de la $K p V$, en relación con la manera como el efecto negativo sobre el influjo de las inclinaciones que produce el sentimiento de respeto (Achtung) a la ley, por medio de la humillación (Demüthigung) a la que nos somete, favorece al mismo tiempo positivamente nuestra determinación por los principios de la moralidad, sosteniendo que «toda disminución de los obstáculos de una actividad es fomento de esa actividad misma» (Kant, 1997: 103; también en Kant, 1989: 25; Kant, 2002b: 40, 250). En segundo lugar, la de que el bien y el mal morales se encuentren en una relación de oposición real y no solamente lógica (Kant, 1986: 201-202; también en Kant, 1987: 51-52). Por este doble motivo es por lo que considero que resulta razonable estimar que del enfrentamiento con el mal moral (el vicio: Laster) resultará el bien moral (la virtud: Tugend), propiciándose 
de esta manera el progreso moral del género humano hacia el ideal de santidad (Heiligkeit) en que consiste su perfección moral mediante este tipo de medidas dirigidas a la censura de las manifestaciones del mal moral en el mundo.

A este modo negativo de proceder en cuanto al desempeño de la función educadora por parte del Estado se le puede achacar que ciertamente podría disuadir contra el comportamiento indecoroso en cuanto a las costumbres, pero de ello no resulta legítimo concluir un necesario aumento de la moralidad en el modo de obrar, pudiendo incluso contribuir su ejercicio a la extensión de las conductas hipócritas dentro de la sociedad, razón tal vez por la cual nuestro autor se refiera a él asignándole el valor de constituir un "paso hacia la moralidad», aunque no se trate todavía de un paso moral. Al respecto, pese a que Kant se refiera a este riesgo exclusivamente en lo que atañe a las relaciones mantenidas entre los Estados, indicando que «antes que se dé este último paso (el de la constitución de una liga de Estados), es decir, casi a la mitad de su formación, la naturaleza humana padece los peores males bajo la apariencia engañosa de nuestro bienestar; y no estaba equivocado Rousseau al preferir el estado de los salvajes si se olvida la última etapa que nuestra especie tiene todavía que remontar» (Kant, 1992a: 56), pienso que esta situación podría asimismo ser aplicable en la consideración de las relaciones que establecen entre sí los individuos concretos que componen los Estados.

\subsection{El «entusiasmo» ante la Revolución francesa}

En sexto lugar se encuentra el que según nuestro parecer probablemente sea el signo más inequívoco que Kant pudiera haber aportado a favor de la tesis que defiende el progreso moral del género humano, consistente en el «entusiasmo» (Enthusiasm) de los espectadores de la Revolución francesa, "cuya manifestación, que lleva aparejada un riesgo, no puede reconocer otra causa que una disposición moral del género humano» (Kant, 1992b: 105-106).

El término «entusiasmo» hace referencia a un sentimiento. En varios lugares de su obra nuestro autor se refiere a los sentimientos, la mayoría de las veces valorándolos negativamente (entre otros en Kant, 1997: 189). Sin embargo, aunque deja claro que en ningún caso les atribuye una capacidad fundamentadora de 
la moralidad ${ }^{2}$, no descarta que éstos puedan ejercer como signos de la misma, como ocurre con el sentimiento de lo sublime analizado en la Analítica del juicio estético de la $K U$ (Kant, 1991: 243, 214-215).

Con anterioridad a emitir un juicio sobre la sentencia kantiana en relación con el índice moral que supuso el sentimiento de entusiasmo ante la Revolución de los que la contemplaron y lo que ello pudiera suponer en relación con la tesis que defiende el progreso moral del género humano, debe analizarse en qué elemento radicaría la supuesta moralidad asociada a tal sentimiento.

Una posibilidad consiste en considerar que es la propia Revolución la que poseyó un carácter moral y que esa moralidad fue la que resultó reconocida por una hipotética facultad humana para el sentimiento moral, de manera que se habría venido a dar una cierta "conexión» entre lo moral del acontecimiento histórico y lo moral del espectador del mismo. Ahora bien, esta posibilidad debe ser rechazada, entre otros motivos porque admitir que eso pudiese haber sido así supondría reconocer, o bien la existencia de una facultad para el sentimiento moral en el hombre dotada de capacidad cognoscitiva, lo que Kant rechaza, o bien la posibilidad de que se diese un particular modo de comunicación entre el ámbito del fenómeno (sentimiento en el hombre) y el del noúmeno (principio moral de la Revolución), posibilidad ésta que nuestro autor seguramente también descartaría calificándola como «misticismo». En el foco de tales rechazos se encuentra el carácter de la intuición humana, que no es intelectual sino sensible, por lo que sólo es capaz de aspirar al conocimiento objetivo en el ámbito del fenómeno y no en el del noúmeno.

\footnotetext{
2 Así, por ejemplo, nuestro autor se refiere al «sentimiento moral», pero no concede a este sentimiento la capacidad de ejercer como guía de la acción, como pretendieron hacer los empiristas ingleses, sino que se limita a otorgarle el mero valor de elemento «a posteriori» que surge una vez que la voluntad humana ya ha sido determinada por el imperativo categórico a la realización de la acción. No obstante, también indica que hay un sentimiento cuya ocurrencia es susceptible de ser anticipada "a priori», siendo éste el del «respeto» (Achtung) ante la ley moral (Kant, 1997: 58-62), que nos hace conscientes de la superioridad y fuerza de la misma ante todos los obstáculos de índole natural que pudieran debilitar el carácter incondicionado del mandato en que consiste el deber moral («La tercera proposición, consecuencia de las dos anteriores, yo la formularía de esta manera: el deber es la necesidad de una acción por respeto a la ley» (Kant, 1990: 63). "No queda, pues, otra cosa que pueda determinar la voluntad más que, objetivamente, la ley, y subjetivamente, el respeto puro a esa ley práctica, y, por lo tanto, la máxima de obedecer siempre a esa ley, incluso con perjuicio de todas mis inclinaciones» (Kant, 1990: 64). "El respeto hacia la ley moral es, pues, el único y al mismo tiempo indudable motor moral, así como también este sentimiento no se dirige a ningún objeto más que sólo por aquel fundamento» (Kant, 1997: 102)).
} 
Siguiendo a Lyotard en su obra El entusiasmo, el elemento de moralidad que podría venir involucrado por los acontecimientos revolucionarios debe buscarse, más que en la apreciación de una supuesta intencionalidad moral por parte de los revolucionarios, en la común presencia de un elemento de desinterés tanto en lo verdaderamente moral (pues ello supone la subordinación de las satisfacciones empíricas al principio de la obediencia al deber) como en la relación de contemplación y atención que los espectadores de la Revolución mantuvieron con ella (pues su entusiasmo era capaz incluso de superar los perjuicios que en su relación con el poder les pudiese ocasionar su compromiso revolucionario, por lo que era indicio de que su interés ante ella -la Revolución- respondía a una motivación de índole exclusivamente moral y no a una de carácter material) (Lyotard, 1987: 64-67, 76). Al respecto, debe también hacerse hincapié en que este mismo entusiasmo como elemento fundamentador de la dimensión moral involucrada en este acontecimiento histórico no habría sido posible en los actores del mismo (los revolucionarios franceses), pues su participación activa en tal episodio revolucionario les incapacitaba para tomar una posición tan suficientemente distante del mismo como para poder juzgarlo de manera desinteresada.

Por este motivo, se debe concluir que no es el hipotético carácter moral de la Revolución el que al ser supuestamente percibido por los espectadores de la misma constituye el elemento sobre el cual pueda fundamentarse la presencia de un elemento de moralidad asociado a ella, sino más bien el modo como estos acontecimientos fueron recibidos por quienes los contemplaron, es decir, el que ellos tuviesen la capacidad de entusiasmarse ante ese curso del tiempo que les tocó vivir y no les resultase indiferente.

Una vez considerado en qué consiste el elemento de moralidad involucrado por la Revolución francesa, es necesario pasar a abordar la cuestión de en qué medida su presencia puede constituir un apoyo a la tesis que defiende el progreso moral del género humano. En concreto, admitiendo, como Kant lo hizo, que el hecho revolucionario revela la existencia de una disposición para la moralidad en el género humano, queda por ver si la presencia de esta disposición, unida al carácter como acontecimiento de la Revolución misma, pueden hablar suficientemente a favor de la tesis que defiende el progreso moral del género humano. Así podría ser en el supuesto de que se considerase que el movimiento revolucionario, al activar esta disposición, dio lugar a un avance desde una situación inicial donde la moralidad tan sólo se encontraba en potencia a una en la que ésta ya estaría desplegándose activamente. Pero tampoco debe olvidarse que el carácter histórico de este progreso lo configura como relativo, no pudiéndose descartar 
que a esa marcha hacia adelante en el orden de la moralidad no le suceda un retroceso en este mismo orden que neutralice lo logrado, o incluso lo devuelva a un estado previo inferior de desarrollo moral.

Puede plantearse entonces en qué podría radicar el progreso moral que supuestamente delataría el sentimiento de entusiasmo ante el acontecimiento revolucionario francés. Como se acaba de indicar, este entusiasmo vale sólo como indicio de la existencia de una disposición moral en la humanidad, pero no puede ejercer como prueba suficiente del progreso moral continuado del género humano, debido a su carácter singular. Sin embargo, dejando aparte la aspiración a obtener un conocimiento de índole moral (el del progreso moral del género humano) a partir de la constatación de la presencia de un sentimiento (el del entusiasmo por la Revolución francesa), estimo que cabe apuntar que tal sentimiento posee una capacidad movilizadora de los hombres en la búsqueda de la promoción universal de la moralidad de manera coordinada. Ahora ya no se trataría de esperar un aumento de la moralidad en el mundo como resultado acumulativo de los progresos morales de los individuos que componen el género humano tomados uno a uno, sino de que el aludido sentimiento puede constituir un elemento que «conexione» los esfuerzos de los individuos en orden al progreso moral, de manera que se establezca una comunicación mutua favorecedora del progreso moral de la humanidad que dé lugar a un suplemento de «energía» moral en el mundo que impulse el desarrollo de la moralidad en él.

\section{La «iglesia invisible» (unsichtbare Kirche) como asociación para el progreso moral del género humano}

El establecimiento de un sistema legal no puede ejemplificar por sí mismo el progreso moral del género humano, pues en último término cualquier legalidad sólo se refiere al aspecto externo del comportamiento y no al interno, que es el moralmente relevante, por cuanto es él el que atañe a la intención del agente. No obstante, aunque nunca pueda ejercer como una prueba suya, ello no quita para que, cuando un sistema legal sea justo, pueda servir tal justicia como indicio de que se está asistiendo a un progreso en la moralidad. Queda por tanto por ver cuál sería la ejemplificación, si ésta pudiera darse, que de manera ineludible constituyese un indicio suficiente del progreso moral del género humano. Esta ejemplificación habría que buscarla dentro del ámbito del noúmeno, pues, como 
se ha reiterado en el presente artículo, el progreso en lo moral remite a este ámbito como aquél en el que, de ser posible, habría de producirse.

De manera paralela a como la conversión moral supone la entrada del hombre individualmente considerado en el terreno de la moralidad, pienso que puede sostenerse que la conformación de una Iglesia invisible (unsichtbare Kirche), de la que Kant habla en sección tercera de la Religión, constituirá precisamente la ejemplificación buscada de la entrada del género humano en su conjunto en la senda de la moralidad creciente y, por tanto, de su progreso moral.

El motivo de tal propuesta se encuentra en que esta «Iglesia invisible» no se constituye como una mera asociación de personas agrupadas en torno a un fin común de orden material que ellas pudieran tener, sino que el objetivo que las mueve a unirse es exclusivamente el fin ideal de la promoción de la moralidad tanto en ellas mismas como en el mundo (Kant, 1986: 102-103), siendo el apoyo mutuo que sus miembros se presten en orden a la superación de los obstáculos que se presenten a la realización del deber moral el medio por el cual tal promoción se llevará a efecto (Kant, 1986: 94). Por otra parte, el carácter ideal de esta Iglesia hace que la participación en la misma tenga que ser voluntaria, aunque no por ello deba olvidarse que la constitución de la misma es «un deber de índole peculiar, no un deber de los hombres para con otros hombres, sino del género humano consigo mismo» (Kant, 1986: 98), conjugándose así de esta manera el ejercicio individual de la libertad por parte de cada uno de sus componentes con el reconocimiento mutuo que hagan de sus respectivas libertades.

La pertenencia a dicha comunidad «invisible» distinguirá presumiblemente a sus miembros por el entusiasmo que pongan a la hora de obrar. En el fundamento de tal entusiasmo se encuentra precisamente el que la participación en esta sociedad sea completamente desinteresada, por lo que el objetivo de la misma (el progreso moral del género humano) resultará ser del máximo interés posible para sus componentes. Este entusiasmo con el que se contribuirá a la realización de los deberes propuestos por esta comunidad constituye finalmente la garantía última de que el progreso moral del género humano es posible, pues supone la posesión de un elemento adicional de fortaleza que permitirá superar los obstáculos que se interpongan en la realización del fin ideal de la perfección humana, haciendo que la aproximación a tal objetivo no precise ninguna «especie de nueva creación", lo que irremediablemente supondría la introducción de un factor de índole sobrenatural en la historia humana. 
De esta manera, se tiene que el entusiasmo del que anteriormente se habló al tratar del sentimiento que en los espectadores de la Revolución francesa ésta ocasionó y cuyo valor se defendió que radicaba en constituir un elemento propiciador y dinamizador del progreso moral de la humanidad por permitir la "conexión» de los esfuerzos individuales dando lugar a un ideal común de progreso moral reaparece en la filosofía de la religión kantiana tomando la forma de «Iglesia invisible» que, convenientemente depurada del ropaje terminológico religioso, representa la "comunidad ética universal» como el ideal moral a cuya realización el género humano se encuentra interpelado.

Finalmente, debe apuntarse que es precisamente en las referencias que Kant hace a la constitución de esta Iglesia invisible donde nuestro autor se muestra más optimista y concluyente en relación con el progreso moral del género humano, cifrando éste en el tránsito progresivo desde la «fe eclesial» a la «Religión universal de la Razón» (Kant, 1986: 125) e indicando que:

Si ahora se pregunta qué tiempo de toda la historia de la iglesia hasta ahora conocida es el mejor, no dudo en decir: es el actual, y lo es de modo que se puede simplemente dejar que se desarrolle más y más, sin impedimento, el germen de la verdadera fe religiosa tal como ahora ha sido puesto, ciertamente sólo por algunos, pero públicamente, en la Cristiandad, para esperar de ello una aproximación continua a aquella iglesia que une para siempre a todos los hombres, la cual constituye la representación visible (el esquema) de un reino de Dios sobre la tierra (Kant, 1986: 134).

Por todo ello, estimamos plausible concluir apuntando que, si bien no contamos con elementos suficientes que nos garanticen el progreso moral del género humano, sí que disponemos de indicios suficientes que permiten conectar el deber de trabajar a favor suyo con la esperanza de que éste es posible, constituyendo tal vez la ausencia de tales elementos probatorios lo que dota precisamente de valor y dignidad a nuestros esfuerzos en orden a la realización de tal ideal de progreso. 


\section{Conclusiones}

Kant no abordó de manera temática la problemática del progreso moral del género humano en ninguna de sus Críticas, sino que las referencias a esta problemática se encuentran dispersas en sus opúsculos dedicados a los temas relacionados con la filosofía de la historia, pero no por ello la temática del progreso moral humano puede ser obviada en el marco de su filosofía crítica.

Tres hipótesis son posibles respecto al cumplimiento del deber de avanzar moralmente: el «terrorismo moral», el «eudemonismo» y el «abderitismo». Aunque no se cuente con elementos empíricos suficientes que la avalen, si se atendiese exclusivamente a cómo son las cosas, parece que esta última hipótesis habría de ser aquélla por la que se decantase cualquier investigador suficientemente maduro y bien informado al respecto. Pero el requerimiento que la razón práctica hace al hombre a favor del bien moral, plantea como un deber de la humanidad el de su mejoramiento moral o progreso en el orden de la moralidad.

En la respuesta a la pregunta acerca de si el género humano progresará moralmente, un elemento de ayuda en su dilucidación lo constituyen las consideraciones kantianas según las cuales es posible anticipar que la humanidad progresará legalmente. Este progreso legal posee la ventaja adicional de que es susceptible de ser comprobado experimentalmente.

No sucede lo mismo con el hipotético progreso moral, ya que no resulta posible obtener conocimiento objetivo alguno dentro del ámbito en el que habría de darse, que es el nouménico. Pero la investigación filosófica ha de indagar si de alguna manera éste podrá darse o no lo hará. Aunque autores como Höffe o Yovel nieguen que unido al progreso legal pueda producirse un progreso equivalente en lo moral, se han expuesto en el presente artículo algunos indicios que podrían sostener de manera razonable que nuestro autor sí que pensó que el género humano progresará en lo moral, estableciendo algunos de ellos esta posibilidad como consecuencia de su progreso en el orden de la legalidad, mientras que otros lo hacen basándose en consideraciones referidas meramente a la moralidad de los individuos. Ninguno de estos indicios posee ciertamente carácter suficiente respecto de la anticipación de tal progreso, e incluso puede sostenerse que a lo sumo lo único que alcanzarían a hacer sería mostrar que efectivamente en el hombre hay una disposición para la moralidad, pero que ésta puede desarrollarse tanto a favor como de manera indiferente respecto del avance moral del género humano. No obstante, desde un punto de vista práctico, estos indicios bastan 
para requerir a cada hombre concreto y a la humanidad en su conjunto para que se conduzca teniendo presente en todo momento como fin de su actuación en el mundo el del mejoramiento moral de la humanidad.

\section{Agradecimientos}

Agradezco la colaboración del profesor Dr. D. Jacinto Rivera de Rosales en la elaboración del presente artículo.

\section{Bibliografía}

Anderson-Gold, Sharon (2001). Unnecessary Evil: History and Moral Progress in the Philosophy of Immanuel Kant, Albany: SUNY Press.

Dupré, Louis (1998). Kant's Theory of History and Progress. The Review of Metaphysics, 51 pp. 813-828.

Jamieson, Dale (2002). Is there Progress in Morality? Utilitas, 14 (3), pp. 318-338.

Kant, Immanuel (1902 y ss.). Immanuel Kants Schriften (Ausgabe der königlich preussischen Akademie der Wissenschaften 29 volúmenes). Berlín: Walter de Gruyter.

- (1985). La paz perpetua (presentación de Antonio Truyol, traducción de Joaquín Abellán). Madrid: Tecnos.

- (1987). Los progresos de la metafísica desde Leibniz y Wolff (traducción de Félix Duque). Madrid: Tecnos.

- (2002). Lecciones de ética (introducción y notas de Roberto Rodríguez Aramayo, traducción de Roberto Rodríguez Aramayo y Concha Panadero). Madrid: Crítica.

- (1992a). Idea de una historia universal en sentido cosmopolita. Filosofia de la historia (prólogo y traducción de Eugenio Ímaz) (1992). Madrid: Fondo de Cultura Económica.

- (1992b). Si el género humano se encuentra en progreso constante hacia mejor. Filosofía de la historia (prólogo y traducción de Eugenio Ímaz) (1992). Madrid: Fondo de Cultura Económica.

- (1993). En torno al tópico: «Tal vez eso sea correcto en teoría, pero no sirve para la práctica» (traducción de M. Francisco Pérez López). Teoría y práctica (estudio preliminar de Roberto Rodríguez Aramayo, traducción de Juan Miguel Palacios, M. Francisco Pérez López y Roberto Rodríguez Aramayo) (1993). Madrid: Tecnos. 
- (1997). Crítica de la razón práctica (traducción de E. Miñana y Villagrasa y Manuel García Morente). Salamanca: Sígueme.

- (2000). Lógica (prefacio de Nobert Hinske, edición de María Jesús Vázquez Lobeiras). Madrid: Akal.

- (1990). Fundamentación de la metafísica de las costumbres (edición de Luis Martínez de Velasco). Madrid: Espasa-Calpe.

- (1986). La religión dentro de los limites de la mera razón (traducción, prólogo y notas de Felipe Martínez Marzoa). Madrid: Alianza Editorial.

- (1989). Critica de la razón pura (prólogo, traducción, notas e índices de Pedro Ribas). Madrid: Alfaguara.

- (1991). Crítica del juicio (edición y traducción de Manuel García Morente). Madrid: Espasa-Calpe.

- (2002). La metafísica de las costumbres (estudio preliminar de Adela Cortina Orts, traducción y notas de Adela Cortina Orts y Jesús Conill Sancho). Madrid: Tecnos.

Kleingeld, Pauline (1999). Kant, History, and the Idea of Moral Development. History of Philosophy Quarterly, 17 (1), pp. 59-80.

Lyotard, Jean-François (1987). El entusiasmo: Critica kantiana de la historia. Barcelona: Gedisa.

Moran, Kate A. (2012). Community and Progress in Kant's Moral Philosophy, Washington, DC: CUA Press.

Santiago Oropeza, Teresa (2016). Kant: La guerra y el progreso moral. Revista De Filosofia Open Insight, 7 (11), pp. 11-33.

Surprenant, Chris W. (2007). Cultivating Virtue: Moral Progress and the Kantian State. Kantian Review, 12 (1), pp. 90-112.

Recibido: 19/03/2018

Aceptado: 19/07/2018

Este trabajo se encuentra bajo una licencia de Creative Commons Reconocimiento-

NoComercial-SinObraDerivada 4.0

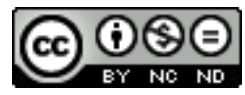


